OPEN ACCESS

Approved by:

Frontiers Editorial Office,

Frontiers Media SA, Switzerland

*Correspondence:

Frontiers Production Office production.office@frontiersin.org

Specialty section:

This article was submitted to

Livestock Genomics,

a section of the journal

Frontiers in Genetics

Received: 11 November 2020

Accepted: 11 November 2020

Published: 07 December 2020

Citation:

Frontiers Production Office (2020) Erratum: Infrared Spectrometry as a

High-Throughput Phenotyping Technology to Predict Complex Traits

in Livestock Systems.

Front. Genet. 11:628196.

doi: 10.3389/fgene.2020.628196

\section{Erratum: Infrared Spectrometry as a High-Throughput Phenotyping Technology to Predict Complex Traits in Livestock Systems}

\section{Frontiers Production Office*}

Frontiers Media SA, Lausanne, Switzerland

Keywords: beef cattle, dairy cattle, near-infrared, novel phenotypes, mid-infrared, spectral information

\section{An Erratum on}

Infrared Spectrometry as a High-Throughput Phenotyping Technology to Predict Complex Traits in Livestock Systems

by Bresolin, T., and Dórea, J. R. R. (2020). Front. Genet. 11:923. doi: 10.3389/fgene.2020.00923

Due to a production error, an incorrect reference citation "Vanlierde et al. (2016)" was inserted in Table 5. It should be "Visentin et al. (2016)." The corrected Table 5 appears below.

The publisher apologizes for this mistake. The original article has been updated.

\section{REFERENCES}

\footnotetext{
Visentin, G., Penasa, M., Gottardo, P., Cassandro, M., and De Marchi, M. (2016). Predictive ability of mid-infrared spectroscopy for major mineral com-position and coagulation traits of bovine milk by using the uninformative variable selection algorithm. J. Dairy Sci. 99, 8137-8145. doi: 10.3168/jds.2016-11053
}

Copyright $(2020$ Frontiers Production Office. This is an open-access article distributed under the terms of the Creative Commons Attribution License (CC BY). The use, distribution or reproduction in other forums is permitted, provided the original author(s) and the copyright owner(s) are credited and that the original publication in this journal is cited, in accordance with accepted academic practice. No use, distribution or reproduction is permitted which does not comply with these terms. 
TABLE 5 | Number of samples (N) and coefficient of determination in the validation set for mineral contents using partial least square methodology.

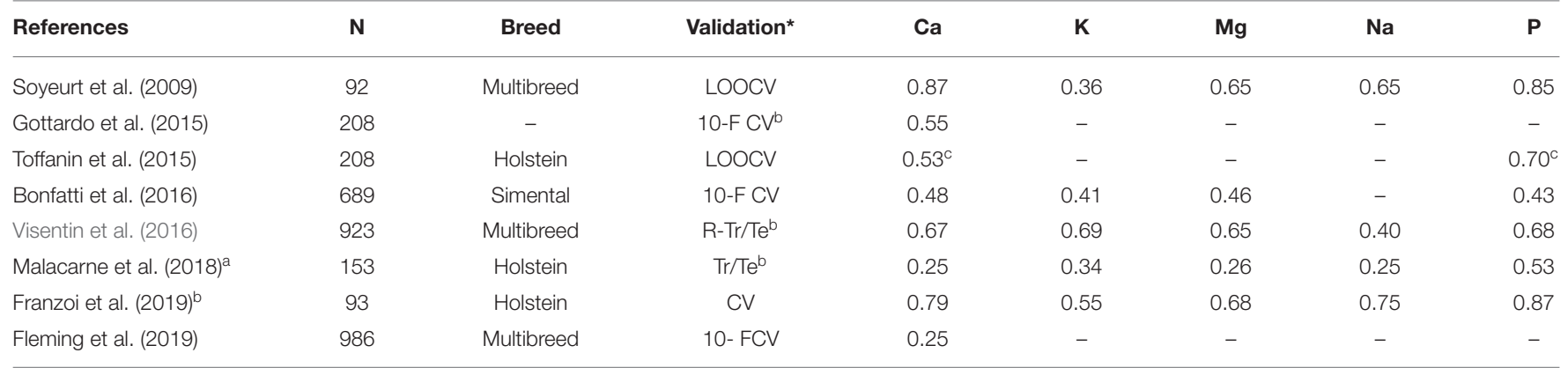

${ }^{a}$ Bulk milk samples. ${ }^{b}$ Backward interval partial least squares (BiPLS), number of folds ( $n$ - $F$ ) in the cross-validation, leave-one-out cross-validation (LOOCV), train and test cross-validation defined by splitting the data set randomly (R-Tr/Te), external or independent validation. ${ }^{C}$ Correlation coefficient (r) transformed to coefficient of determination (R2). *The validation strategy defined as " $\mathrm{CV}$ " was assigned for the reviewed paper that did not completely describe the validation method adopted or the authors defined that cross-validation was employed. 